Article

\title{
A Numerical Study of Mountain-Plain Breeze Circulation in Eastern Chengdu, China
}

\author{
Yue Tian and Junfeng Miao * \\ Key Laboratory of Meteorological Disaster of Ministry of Education, Nanjing University of Information Science \\ and Technology, 219 Ningliu Road, Nanjing 210044, China; tianyue0704@163.com \\ * Correspondence: miaoj@nuist.edu.cn
}

Received: 1 April 2019; Accepted: 14 May 2019; Published: 17 May 2019

\begin{abstract}
The spatiotemporal structure and evolution of the thermally-induced mountain-plain breeze circulation in the Longquan Mountain, eastern Chengdu, are studied by the WRF-ARW model based on a two-day case. Turbulence characteristics are also examined to better understand the local circulation of the area. Simulation results show that the $2 \mathrm{~m}$ temperature distribution of the plain and mountain areas is peculiar due to the occurrence of the temperature inversion. The plain and mountain breezes can be predicted explicitly by the model, and the consequent circulations are coupled with other factors such as turbulent movement and vertically propagating mountain waves. Owing to this unique terrain feature, the north portion of the mountain demonstrates more evident mountain and plain breezes compared to the south and middle portions. Stronger turbulences are formed over the mountain area compared to the plain area. Vertical cross-sections of turbulent heat, moisture and momentum fluxes show that turbulent transport plays an important role in the development and elimination of mountain-plain breeze circulation.
\end{abstract}

Keywords: complex terrain; mountain-valley breeze; turbulence characteristics; high-resolution numerical modeling; Sichuan Basin

\section{Introduction}

Mountain wind system occurs at mountainous regions and has a great effect on regional climate, weather, environment and natural resources [1-5]. It comprises of slope breeze, valley breeze and mountain-plain breeze, which all experience wind direction changes twice a day under weak synoptic forcing, and clear-sky conditions [6-9]. In complex mountain ranges such as the Alps and the Pyrenees [10], the three components coexist and dominate different areas of the mountain, respectively. Extensive research regarding the impact of surface conditions and synoptic background on the mountain wind system has been carried out in many other places around the world [11-14].

The Longquan Mountain (103.6-104.7 ${ }^{\circ}$ E, 29.6-31.4 $\mathrm{N}$ ) is located in eastern Chengdu, with an approximate length of $200 \mathrm{~km}$ and width of $10 \mathrm{~km}$, oriented in the southwest-northeast direction. The average height of the mountain is less than $1 \mathrm{~km}$, and the maximum height is about $1051 \mathrm{~m}$. Compared to those large mountain ranges, its topography and terrain are simpler. Therefore, the local wind field is mainly affected by the mountain-plain breeze of the Longquan Mountain, characterized with plain breeze (perpendicular to the mountain range, blowing from the plain to the mountain) in the daytime and mountain breeze (perpendicular to the mountain range, blowing from the mountain to the plain) in the nighttime. The Longquan Mountain is the geographical division between the Chengdu plain and the hilly area in the east, which are called the western plain and eastern plain in this study, respectively. Besides, there is the Longmen Mountain in the west of the Chengdu plain and all of the above are located in the Sichuan Basin. In these topographic conditions, the characteristics of the mountain-plain breeze circulation of the Longquan Mountain remain unclear. 
Studies regarding turbulence in the mountain area have also been carried out widely because of the complexity of the turbulent characteristics, the observational and parameterized difficulties, and the vertical mixing effects on the air pollutants [15-17]. Lehner and Rotach [18] discussed in detail the progress and challenges of the turbulent transport and exchange processes of momentum, heat energy and mass in the mountain boundary layer. On one hand, turbulent flows advected by thermally-driven slope and valley breezes may contribute to the instability of the mountain boundary layer, leading to stronger vertical transport of moisture and pollutants [19]. On the other hand, turbulences caused by breaking mountain waves are common in large mountain ranges, and in more serious cases, leading to aircraft accidents $[20,21]$. The Longquan Mountain is not as high as the mountain in Scandinavia, where it can lead to strong mountain lee waves and turbulent movements, yet we can still learn the turbulent transfer of the momentum, heat, and moisture for a better understanding of the formation and evolution of the local circulation.

Even though the mountain wind system has been extensively studied over the past years, to our knowledge, very few pieces of research can be found in eastern Chengdu, let alone modeling efforts. As the economic and industrial center of western China, Chengdu has experienced rapid urbanization, leading to increasing pollution problems. Research regarding the topographical and meteorological factors that exacerbate this pollution is needed. For these reasons, numerical simulation results of meteorological elements and turbulence characteristics around the Longquan Mountain are explained in detail in this paper.

\section{Data and Methods}

\subsection{Surface Observational Data}

Observational data from five basic-reference stations in the D4 area are used to examine the validity of the simulation results. Wenjiang station $\left(103.86^{\circ} \mathrm{E}, 30.75^{\circ} \mathrm{N}\right)$ is identified as a radiosonde station with twice daily soundings at 08:00 LST and 20:00 LST. The remaining stations are selected along the Longquan Mountain, respectively are: Jianyang $\left(104.55^{\circ} \mathrm{E}, 30.38^{\circ} \mathrm{N}\right)$, Jintang $\left(104.43^{\circ} \mathrm{E}\right.$, $\left.30.85^{\circ} \mathrm{N}\right)$, Longquan $\left(104.25^{\circ} \mathrm{E}, 30.55^{\circ} \mathrm{N}\right)$, Xindu $\left(104.15^{\circ} \mathrm{E}, 30.83^{\circ} \mathrm{N}\right)$.

Intensive automatic meteorological observational data is also used in this study to verify surface temperature distribution. The data is examined by the logical extreme check method. Unqualified and missing data are excluded, obtaining 240 effective stations. A critical height of $495 \mathrm{~m}$ is set to provide a rough comparison of the surface temperature between the mountain and the plain area (the average terrain height of D4 is $492 \mathrm{~m}$ ). Hence, 116 mountain stations and 124 plain stations are obtained.

\subsection{Case Description}

Two consecutive days (from 08:00 LST 1 to 08:00 LST 3 October 2016, local standard time: $\mathrm{UTC}+8$, the same below) are selected in this paper for studying the mountain-plain breeze circulation. This period is in early autumn and characterized with a clear-sky, no-precipitation and weak isobaric gradient, which are favorable for the occurrence of local mesoscale circulation. According to the NCEP FNL (National Centers for Environmental Prediction Final) data, on $500 \mathrm{hPa}$, western China was dominated by a high-pressure system which was gradually progressing eastward in this two-day period. On both the $850 \mathrm{hPa}$ and surface layer, Chengdu is at the eastern edge of the high pressure, representing a stable, undisturbed weather situation (Figure 1).

Surface data from the meteorological base stations shows that the surface wind field is predominated by southerly wind in these two days. The temperature field exhibits regular diurnal variation. The temperature of the eastern plain is higher than that of the western plain during the daytime. While during the nighttime, the temperature of the western plain appears higher due to the urban heat island effect. This is in accordance with the conclusion of Zeng [22]. By analyzing MODIS (Moderate Resolution Imaging Spectroradiometer) MOD11A2 remote sensing data from 2002 and 2012, it is found that the strongest intensity of urban heat island of Chengdu appears at night. 

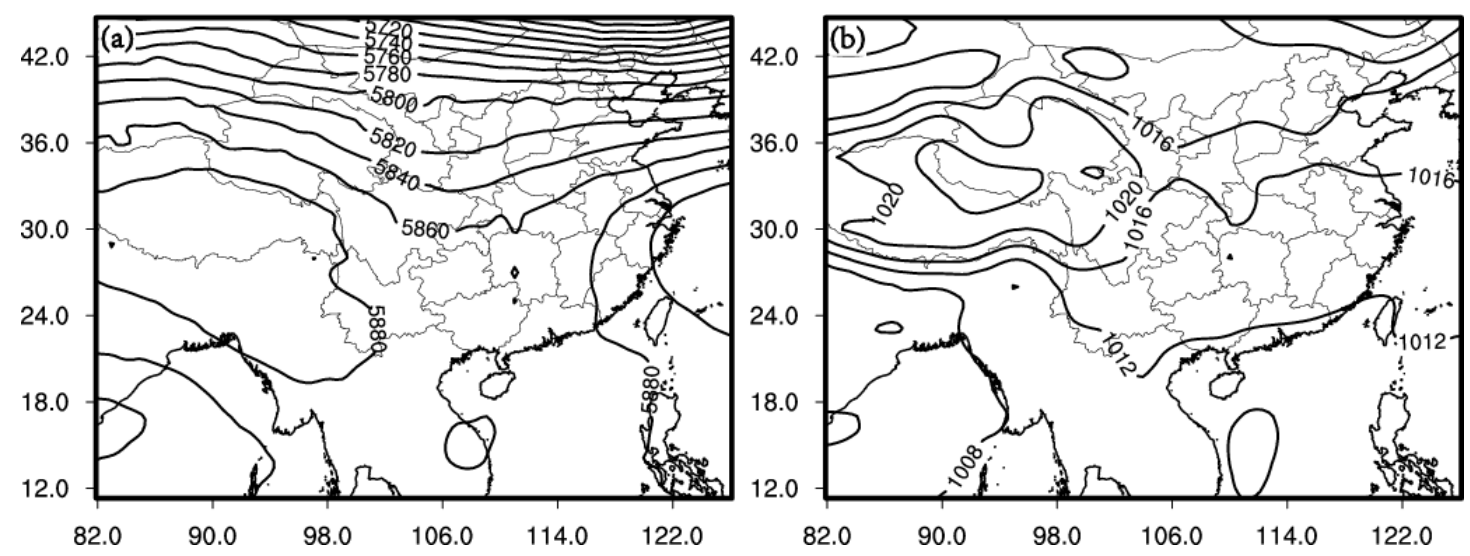

Figure 1. (a) $500 \mathrm{hPa}$ geopotential height field (units: dagpm) and (b) sea surface pressure field (units: hPa) at 08:00 LST on 1 October 2016.

Wind sounding data from Wenjiang station shows that the wind direction is comparatively stable on these two days. The wind speed indicates a subtle background wind, especially below $3 \mathrm{~km}$. Temperature profiles show that during the two days, an inversion layer exists near the surface. This phenomenon in Chengdu has been discovered and widely studied. At 08:00 LST of both days, due to surface radiative cooling at night, the inversion layer grows thicker. At 08:00 LST on 1 October, the thickness is about $400 \mathrm{~m}$ and the strength is about $0.5^{\circ} \mathrm{C} / 100 \mathrm{~m}$. On 2 October (not shown), the thickness is $300 \mathrm{~m}$ and the strength is about $1.5^{\circ} \mathrm{C} / 100 \mathrm{~m}$. In contrast, the inversion layer is much thinner in the daytime and early evening. In short, the stable boundary layer and the synoptic situation based on high-pressure system both make this two-day period a suitable case for the simulation research of mountain-plain breeze circulation.

\subsection{Model Setup}

The Weather Research and Forecasting model (WRF-ARW version 3.9) is used to investigate the three-dimensional structure, evolution and turbulence characteristics of the mountain-plain breeze circulation in the study area. The WRF model is evolved from the Penn State University/NCAR Mesoscale Model (MM5) and is one of the most widely used meteorological models for both operational forecasting and scientific research. The NCEP FNL operational global analysis data with a spatial resolution of $1^{\circ} \times 1^{\circ}$ and a temporal resolution of $6 \mathrm{~h}$ is used to define the initial and boundary conditions. The simulation started at 08:00 LST on 30 September 2016, ends at 08:00 LST on 3 October 2016. The first $24 \mathrm{~h}$ is treated as a spin-up time to preclude the possible errors related to the initial adjustment. The following $48 \mathrm{~h}$ is considered for the analysis.

Efforts have been cast in finding the proper model configuration to reproduce more accurate representations of meteorological processes in mountain regions, pointing out that finer resolution and grid-nesting technique are essential to capture the mesoscale and local scale circulations $[23,24]$. Thus, in this study, the topography information adopted in the preprocessing system is derived from the United States Geological Survey/National Geospatial-Intelligence Agency Global Multi-resolution Terrain Elevation Data 2010 (USGS/NGA GMTED2010_30s). The land use information is from National Aeronautics and Space Administration (NASA) Moderate Resolution Imaging Spectroradiometer (MODIS) with spatial resolutions of 10, 5, 2 arc-min and 30 arc-sec for D1, D2, D3, and D4, respectively. Four model domains are centered at the ridge of the Longquan Mountain $\left(104.36^{\circ} \mathrm{E}, 30.57^{\circ} \mathrm{N}\right)$, with the resolutions of $27 \mathrm{~km}, 9 \mathrm{~km}, 3 \mathrm{~km}$ and $1 \mathrm{~km}$, respectively (Figure 2a). The coarse domain (D1) encompasses the whole of China and is applied to reproduce the synoptic features of the selected case. The finer domain covers the Longquan Mountain in Chengdu. To minimize the negative effects of the lateral boundary and meanwhile reduce the computing cost, the four domains are nested layer by layer with two-way feedback. All four domains include 35 vertical sigma levels, 24 of which are located in 
the lower $2 \mathrm{~km}$, so as to capture the atmospheric boundary layer characteristics. The pressure of the model top is $100 \mathrm{hPa}$. Simulation results are outputted per hour.
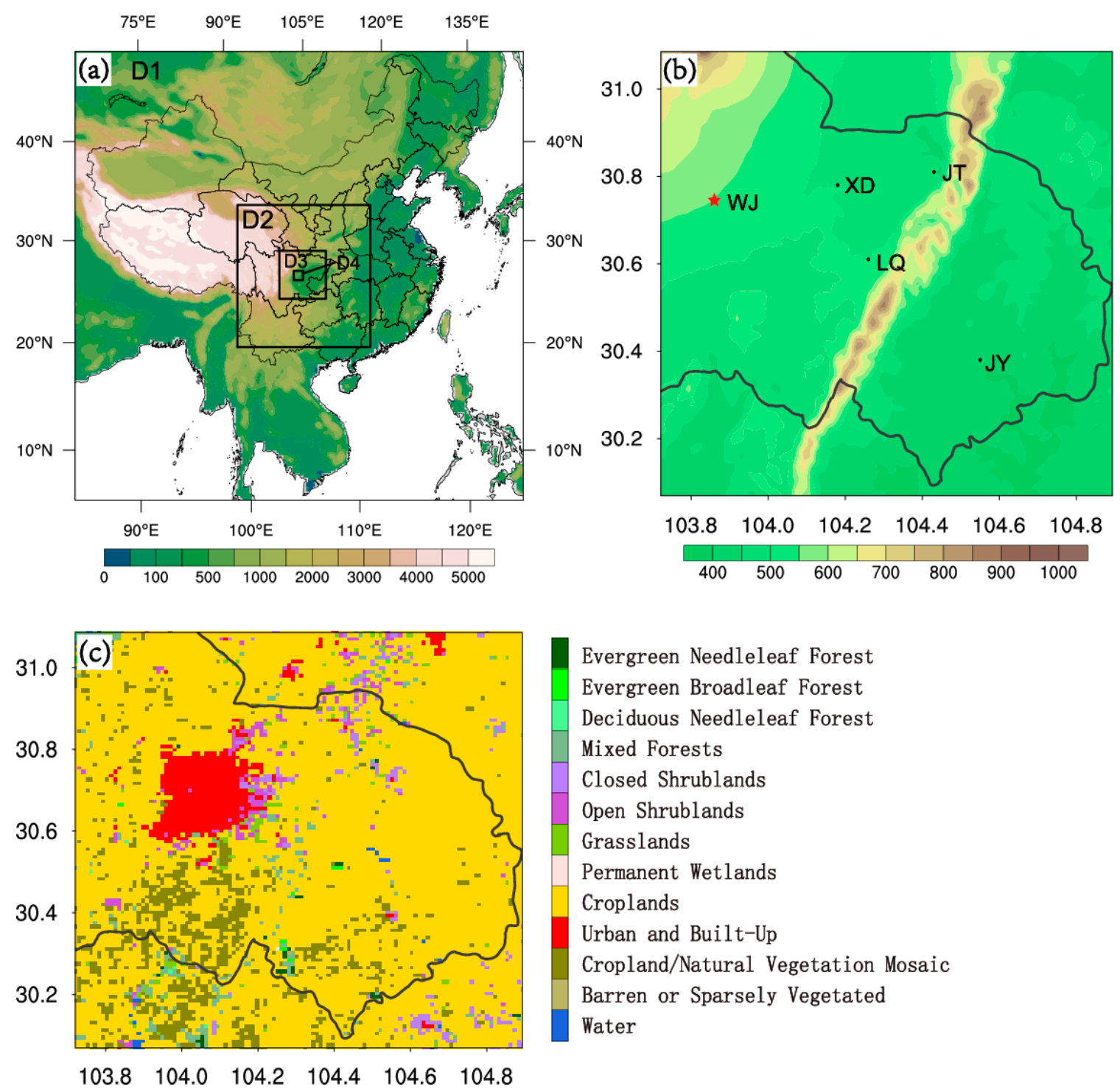

Evergreen Needleleaf Forest

Evergreen Broadleaf Forest

Deciduous Needleleaf Forest

Mixed Forests

Closed Shrublands

Open Shrublands

Grasslands

Permanent Wetlands

Croplands

Urban and Built-Up

Cropland/Natural Vegetation Mosaic

Barren or Sparsely Vegetated

Water

Figure 2. (a) Model domains (D1, D2, D3, D4), shading represents terrain height (units: m); (b) terrain height of D4 (shaded, units: $\mathrm{m}$ ) and locations of five weather stations (XD: Xindu; JT: Jintang; LQ: Longquan; JY: Jianyang; WJ: Wenjiang); (c) land use type of D4.

The WRF model comprises various physical process parameterizations, which can be customized depending on the study area and processes [25]. The parametrization schemes used in this study are shown in Table 1. This combination is proved to work best in the eastern Chengdu area after a series of experiments (not shown in this paper). In the mountainous area, the surface energy budget is much more complicated due to the influence of slope angle, aspect, shading, etc. [19]. In order to get optimal results of the radiation distribution, topographic effects of radiation parameterization scheme are considered in D4. RRTMG (Rapid Radiative Transfer Model for General Circulation Models) is derived from the RRTM scheme, with a higher calculation accuracy and better representation of atmospheric components such as water vapor, ozone, greenhouse gases aerosols, etc. [26]. As for PBL parameterization, the BouLac scheme is a 1.5-order, local closure scheme [27]. It applies local mixing with local diffusivity for both the convective boundary layer and the stable boundary layer [28]. The planetary boundary layer height is diagnosed when the turbulent kinetic energy (TKE) reaches 
a sufficiently small value $\left(0.005 \mathrm{~m}^{2} / \mathrm{s}^{2}\right.$ in this version). Večenaj et al. [29] compared five simulations with different turbulence parameterization schemes (MYJ, QNSE, MYNN2.5, MYNN3, BouLac) and concluded that the simulation using the BouLac scheme reproduced the TKE structure the best. It was also found that the BouLac scheme has a better representation of the boundary layer in the higher static stability regime, than in non-local schemes [28]. Yang et al. [30] compared eight boundary layer parameterizations (YSU, MYNN2.5, MYNN3, ACM2, BouLac, UW, SH, GRM) and found that the BouLac scheme simulates the nocturnal wind pattern better. In addition, of all the PBL schemes provided by WRF V3.9, turbulent fluxes can be directly outputted from the BouLac scheme.

For surface layer parameterization, Prasad et al. [31] compared two sets of simulations using the MM5 surface layer similarity scheme coupled with the YSU PBL scheme and the Eta similarity scheme coupled with the MYJ PBL scheme, indicating that the Eta scheme predicted stronger winds than the MM5 scheme by about 20\%, and the MM5 showed better agreement with the observations whether in wind or in surface temperature fields. Wang and Miao [32] discussed the performance of MM5 and Eta scheme both coupled with BouLac scheme and found the similar results that the Eta simulated stronger sea breeze and surface heat fluxes. Also, compared to the Eta, the MM5-similarity scheme is more long-developed and well-researched [30]. Hence the MM5 scheme is adopted for the surface layer parameterization in this work.

Table 1. Physical process parameterization schemes used in this study.

\begin{tabular}{ll}
\hline Physics Process & Parameterization Option \\
\hline Shortwave radiation & RRTMG \\
Longwave radiation & RRTMG \\
Microphysical process & Lin et al. \\
Cumulus (only in D1) & Kain-Fritsch \\
Boundary Layer & BouLac \\
Surface Layer & MM5 similarity \\
Land surface process & Noah+UCM \\
\hline
\end{tabular}

\section{Results and Discussion}

\subsection{Comparison with Observations}

The model performance over the two days is first evaluated with the sounding data of Wenjiang station. As shown in Figure 3, the inversion layer near the surface is captured, except for 08:00 LST 1 October. The intensities of the simulated inversion layer of the other three times are a bit weaker compared to the observations. On 1 October, simulated temperatures of the upper layer are quite close to the observations, while temperatures from $1500 \mathrm{~m}$ to $3000 \mathrm{~m}$ on 2 October are overrated, and above $3500 \mathrm{~m}$ are underrated (not shown). As for the wind profile, the characteristics of calm wind near the surface are well represented by the model. The whole layer atmosphere of the former day agrees well with the sounding data. On 2 October, the observed wind of the upper layer changes slightly from northerly to westerly, while the transition shown by the simulation results is a bit late. 

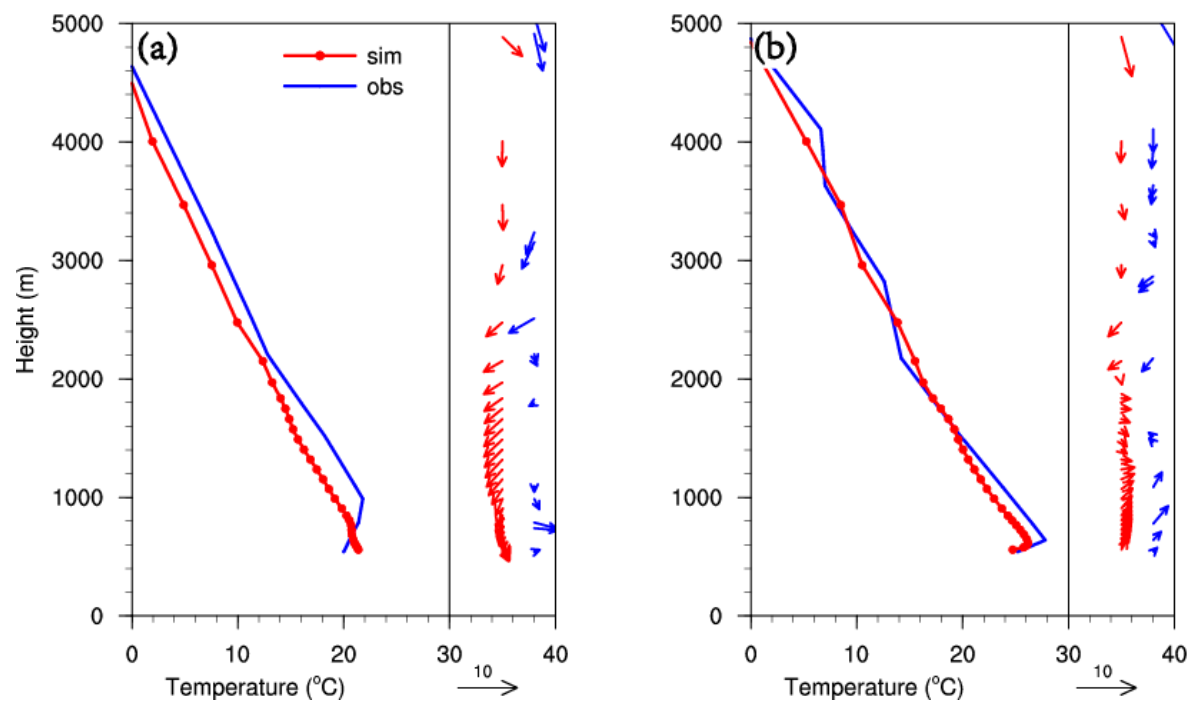

Figure 3. Comparisons between simulated and observed temperature (units: ${ }^{\circ} \mathrm{C}$ ) and wind profile (units: $\mathrm{m} / \mathrm{s}$ ) of Wenjiang weather station (WJ) at (a) 08:00 LST and (b) 20:00 LST on 1 October 2016.

The time series of $2 \mathrm{~m}$ air temperature, $10 \mathrm{~m}$ wind speed and wind direction for the simulation are obtained from the grid point in D4 closest to each station. The comparison between the simulated and observed $2 \mathrm{~m}$ temperature shows that the model reproduces the hourly $2 \mathrm{~m}$ temperature trend reasonably (Figure 4). In the early morning and daytime of the two days, the model underestimates temperatures by $1-2{ }^{\circ} \mathrm{C}$. The simulated nighttime cooling rate of $2 \mathrm{~m}$ temperature is slightly larger than the observation. While in the other periods of the days, the model displays more accuracy, except for the Jianyang station, where the maximum deviation between simulation and observation can reach $3.2^{\circ} \mathrm{C}$. The discrepancy might be caused by the difference between model terrain height and actual elevation. Moreover, the air temperature at Jianyang might be affected by the Tuojiang River, which is not reflected in the land use data.
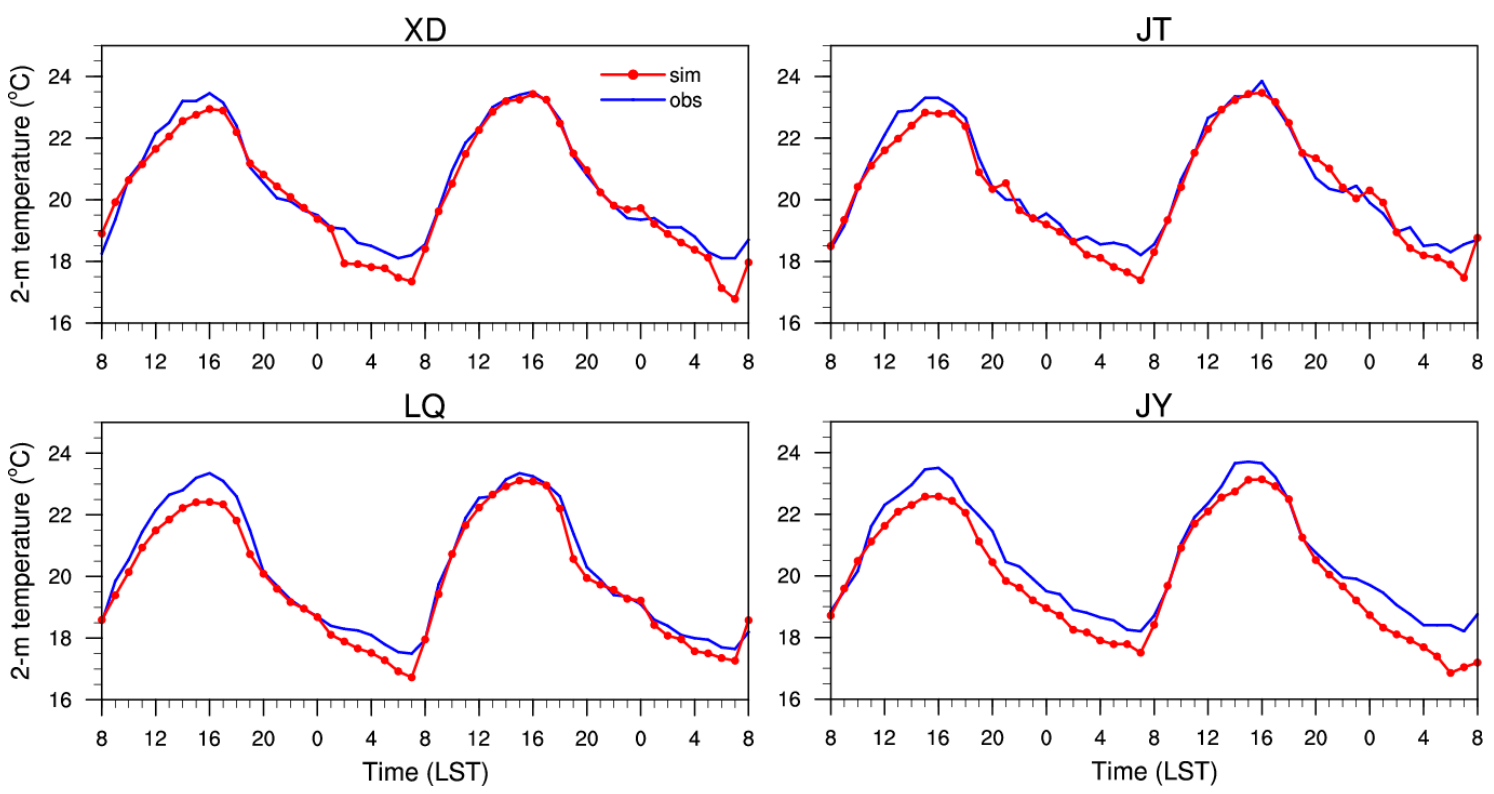

Figure 4. Comparisons between simulated and observed $2 \mathrm{~m}$ temperature (units: ${ }^{\circ} \mathrm{C}$ ) of four weather stations (XD, JT, LQ, JY).

Since the mountain oriented in the southwest-northeast as shown in Figure 2b, the wind direction range of the plain breeze on the west side of the Longquan Mountain is identified as $210-30^{\circ}$, and 
similarly, $30-210^{\circ}$ on the east side. The mountain breeze is defined to the contrary. Jintang, Longquan are most affected by the Longquan Mountain. From the observed wind direction of the two stations, diurnal variation from the southwest at night to the south-southeast at day can be clearly recognized under the circumstance of prevailing southwesterly wind (Figure 5). Comparing simulated wind direction with the observation, it is notable that the simulations show less diurnal variation over the two days. As for the wind speed in Figure 6, the simulated pattern is slightly lagging compared to the observations. Moreover, the model predicts stronger airflow during the day. This phenomenon has been reported by many previous papers and improvement measures have been carried out effectively [33].

The vertical and near-surface characteristics obtained from the model result show an adequate representation of the regional boundary layer behavior and development despite understandable bias. Thus, the simulation result can be used to study the three-dimensional characteristics of the mountain-plain breeze circulation around the Longquan Mountain.
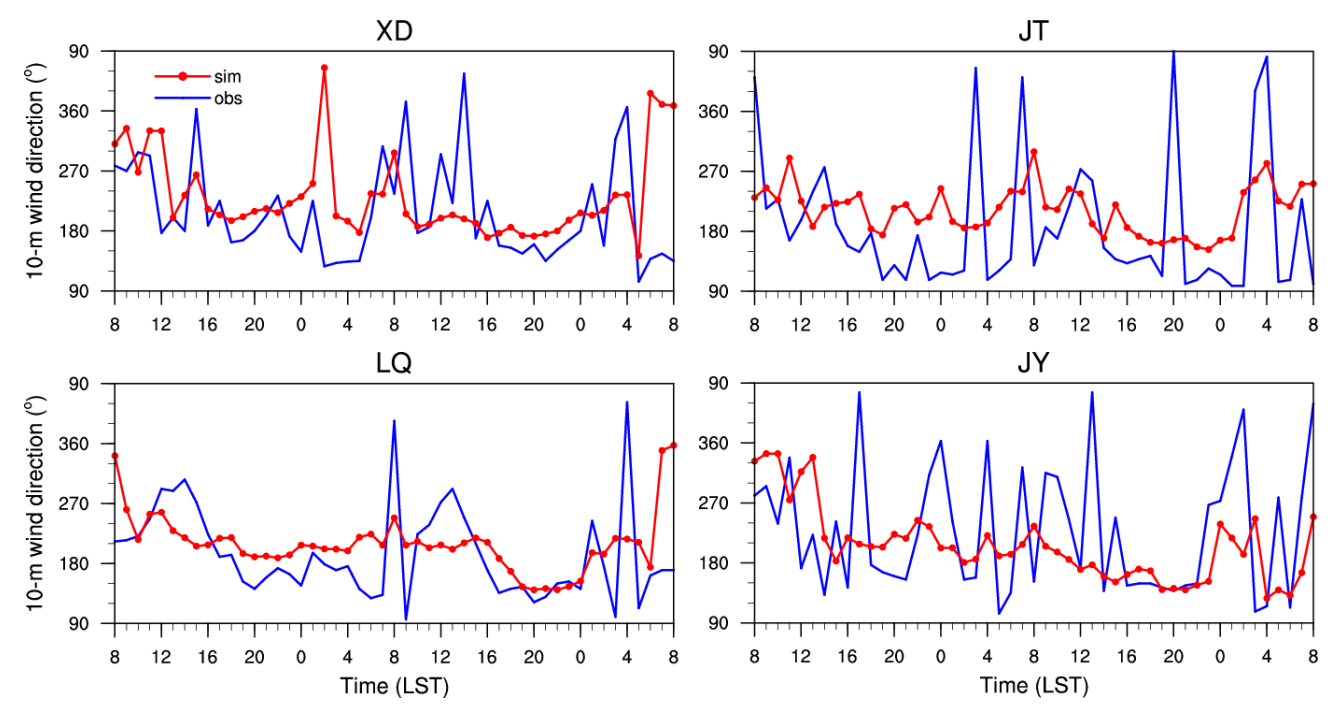

Figure 5. Same as Figure 4, but for $10 \mathrm{~m}$ wind direction (units: ${ }^{\circ}$ ).
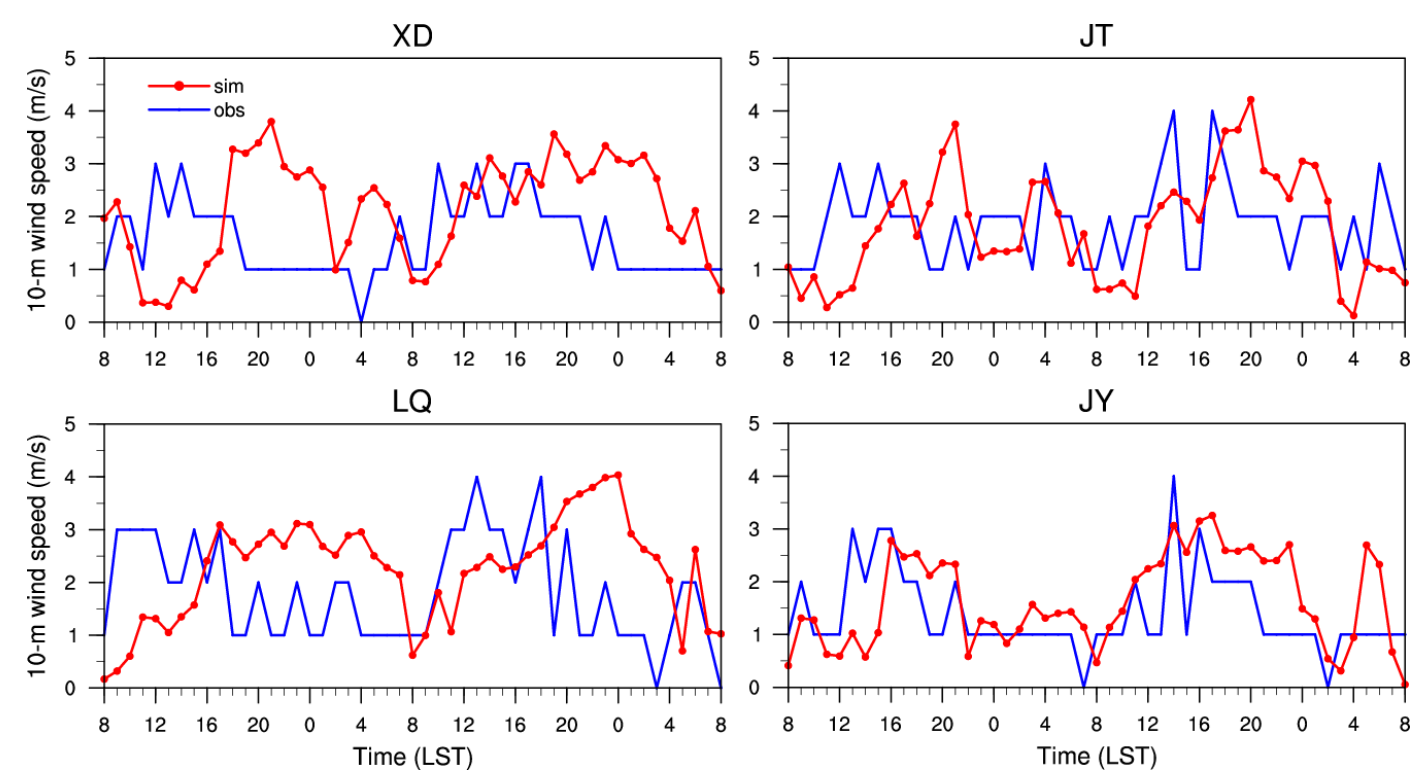

Figure 6. Same as Figure 4, but for $10 \mathrm{~m}$ wind speed (units: m/s). 


\subsection{Horizontal Structure}

Since the two consecutive days show similar features of wind and temperature field in Figures 4-6, the meteorological fields from 08:00 LST 1 October to 08:00 LST 2 October are mainly analyzed. The results of the second day are treated as verification and supplementary explanation.

As shown in Figure 7, there is a significant thermal contrast between mountain and plain area. For most time of the day, the $2 \mathrm{~m}$ temperature over the mountain area is lower than that over the plain area due to the higher altitude. At 10:00 LST, air parcels over the mountain are heated faster than the plain air at the same height, causing flows to move from both sides of the mountain to the ridge, i.e., the plain breeze. The plain breezes are more noticeable in the north and south portion of the mountain, compared to the middle portion where the terrain elevation is lower and intercepted by the Tuojiang River. With the constant surface heating during the day, the turbulent movement near the ground is enhanced, favoring the increase of surface wind speed (Figure 7b). At 17:00 LST, the plain breeze in the south portion starts to weaken and is gradually replaced with mountain breeze. The plain breeze in the north portion, by contrast, can persist until 18:00 LST. For the nighttime and early morning periods (from approximately 19:00 LST to 07:00 LST of the next day), the model simulates a well-defined mountain breeze due to the nighttime cooling effect. At this period of time, coinciding with the location of urban and build-up shown in the land use map, the temperature in the urban area of Chengdu is higher compared to the rural area. Liu et al. [34] showed that at the urban area, the warming effect decreased slower compared to the rural area at night, resulting in higher temperature as known as urban heat island.
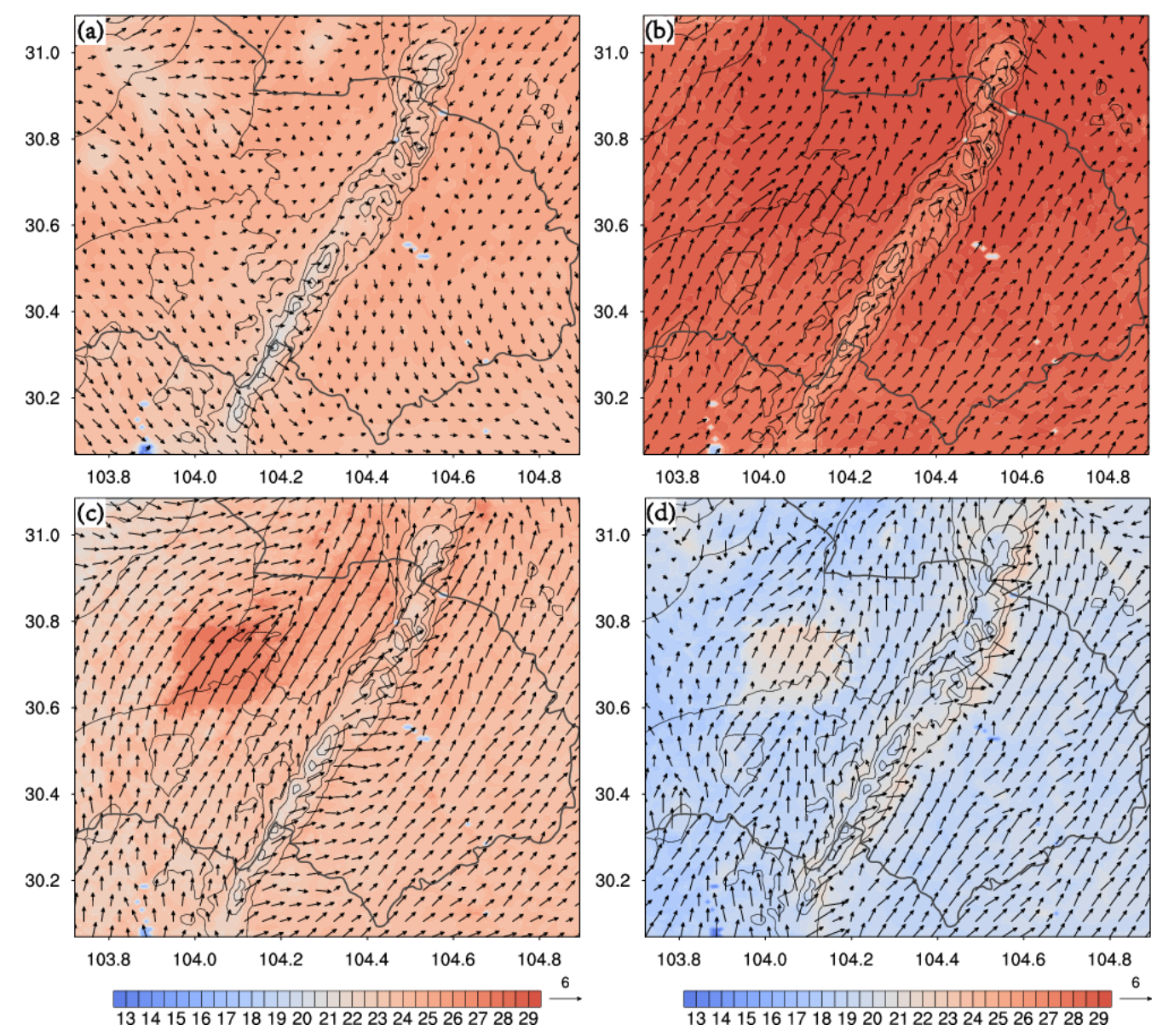

Figure 7. Simulated 10-m wind field (vector, units: $\mathrm{m} / \mathrm{s}$ ), 2 -m temperature (shaded, units: ${ }^{\circ} \mathrm{C}$ ) at (a) 10:00 LST, (b) 16:00 LST, (c) 20:00 LST on 1 October, and (d) 04:00 LST on 2 October 2016; contour: terrain height. 
It is worth noting that, in Figure $7 \mathrm{~d}$, higher temperatures are found over the mountain slope area. This phenomenon is uncommon because the mountain terrain rises higher than the plain and thus normally results in lower surface temperature. Intensive automatic meteorological observational data is used to examine this phenomenon. As seen from Figure 8a,b, the observed curves for both mountain and plain temperature are higher than the simulated ones. This corroborates what we found in Figure 4-that the model tends to underestimate the temperatures in most time of the day. In the daytime, the mountain temperature is lower than the plain temperature for both simulated and observed curves, whereas the model tends to weaken the temperature difference between the mountain and the plain compared to the observations (Figure 8c). During the night of the two days (around 20:00 LST to 09:00 LST of the next day), the averaged $2 \mathrm{~m}$ temperatures in the mountain area are higher than that in the plain, which confirms our finding in Figure 7. The cause of this phenomenon is the steady inversion layer in the Chengdu plain. Within the inversion layer, the air temperature gradually rises with increasing height and thus, resulting in lower surface temperature over the plain area and the higher surface temperature over the mountain slope. Furthermore, it can be found that the observed temperature difference between the mountain and plain reaches the maximum in the first half of the night, while the simulated one reaches the maximum later.
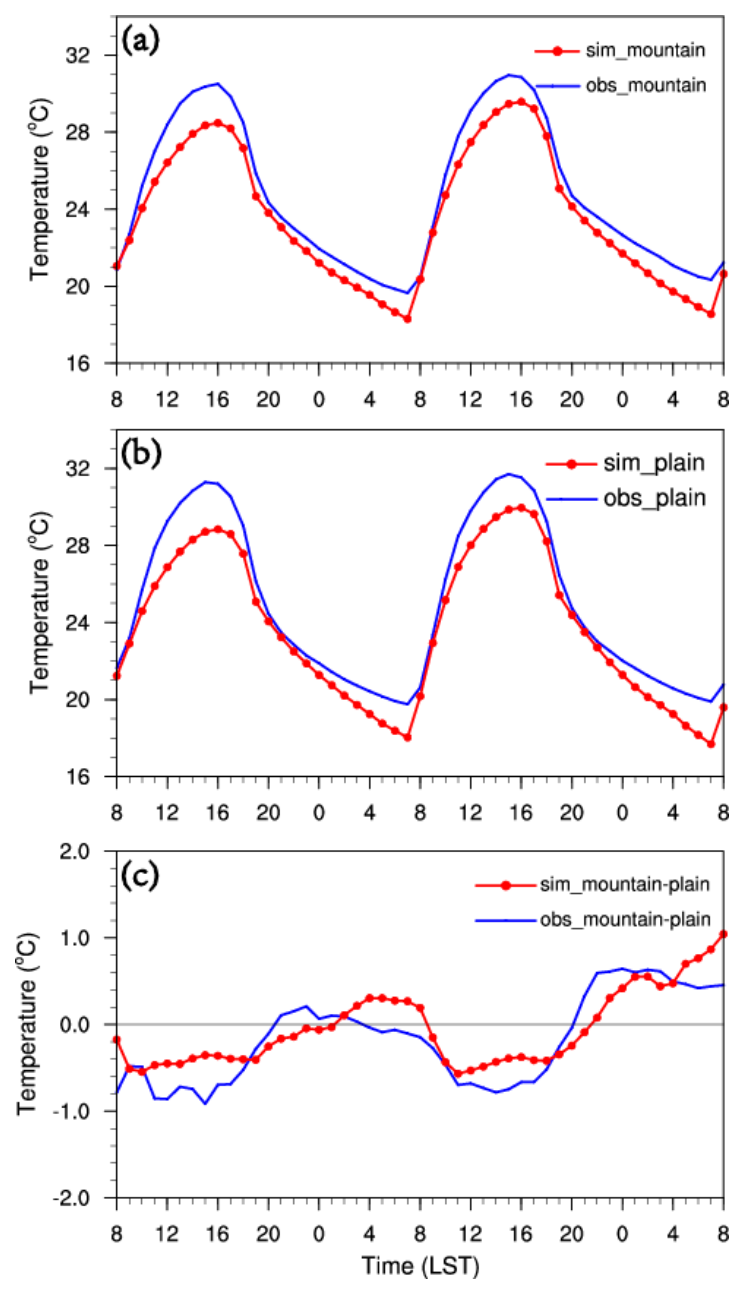

Figure 8. Diurnal evolution of simulated and observed $2 \mathrm{~m}$ temperature (units: ${ }^{\circ} \mathrm{C}$ ) (a) averaged over mountain area (excluding Longmen Mountain) and (b) plain area and (c) difference between mountain and plain (mountain minus plain).

To further scrutinize the different characteristics of the mountain-valley winds in each portion of the Longquan Mountain, time-zonal cross sections of $\mathrm{U}$ - and V-components along latitude $30.9^{\circ} \mathrm{N}$, 
$30.7^{\circ} \mathrm{N}$, and $30.4^{\circ} \mathrm{N}$ are examined as the representatives of the north, middle, south portion, respectively. Along $30.9^{\circ} \mathrm{N}$ (Figure 9a), the cross-section of the mountain terrain height is higher and wider compared to the other selected latitudes. The U-components of the winds on both sides of the mountain exhibit periodic changes over time. The convergence flows are symmetrically distributed along the top of the mountain during most of the daytime, from 08:00 to 17:00 LST on 1 October and from 11:00 to 17:00 LST on 2 October, lasting for about $5-7 \mathrm{~h}$. The convergence flow starts turning into divergence flow at around 22:00 LST on 1 October and 18:00 LST on 2 October, lasting for about 10-14 h. It is worthwhile mentioning that the onset time, the end time of the mountain-valley breeze and the wind field characteristics on both sides of the mountain vary slightly over the two days. This is particularly evident in the wind strength. The divergence flow on the east slope is stronger than that on the west slope due to the enhancement by the prevailing westerly wind on one hand. On the other hand, this phenomenon might be connected with vertically propagating mountain wave, and will be described in detail in the following pages.

In comparison, the cross-sections along latitude $30.7^{\circ} \mathrm{N}$ and $30.4^{\circ} \mathrm{N}$ are less capable to reflect the cyclical changes. The mountain terrain at $30.7^{\circ} \mathrm{N}$ is shorter compared to $30.9^{\circ} \mathrm{N}$ and corrugated with shallow valleys, which is insufficient to induce the regular daily wind shift. Along $30.4^{\circ} \mathrm{N}$, the convergence, divergence flows, and wind shifts are harder to recognize compared to $30.9^{\circ} \mathrm{N}$. The differences of wind fields among each portion of the mountain prove the impact of the topographic condition on the mountain-valley breeze.
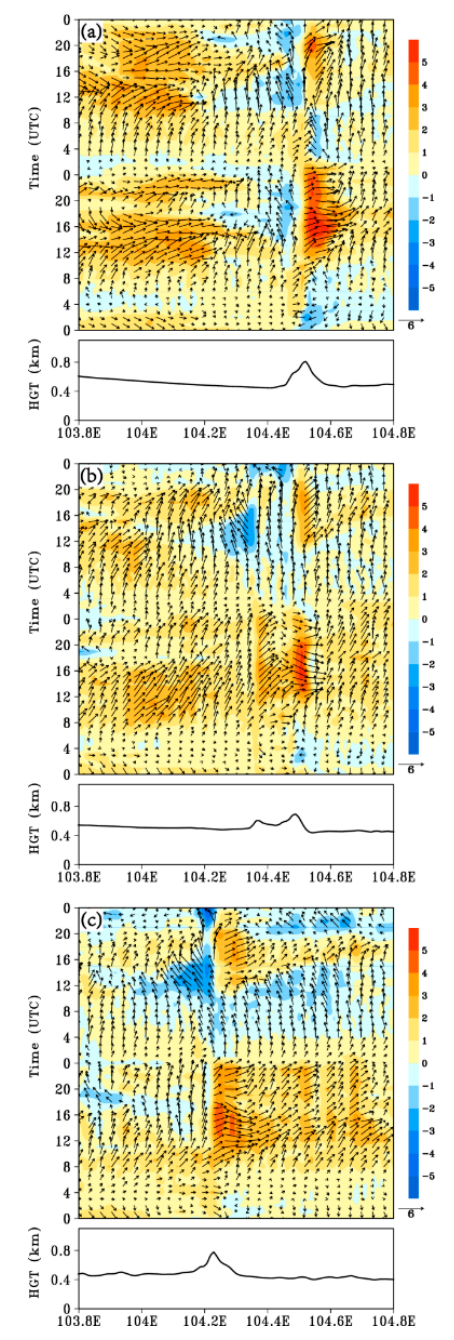

Figure 9. Time-zonal cross-sections of simulated zonal wind (shaded, units: $\mathrm{m} / \mathrm{s}$ ), $10 \mathrm{~m}$ wind field (vector, units: $\mathrm{m} / \mathrm{s}$ ) and terrain height (units: $\mathrm{km}$ ) at (a) $30.9^{\circ} \mathrm{N} ;\left(\right.$ b) $30.7^{\circ} \mathrm{N}$; (c) $30.4^{\circ} \mathrm{N}$. 


\subsection{Vertical Structure}

Horizontal convergence inevitably leads to vertical motion. Figure 10 shows the vertical wind on the first model level at each time corresponding with Figure 7. In Figure 10b, as the surface longwave radiation continues to heat up the atmosphere after sunrise, stronger upflows are formed, especially in the north portion of the mountain, which supports the obvious convergences in the day found in Figure 9a. While in the middle portion, only weak vertical motion with speed of $-0.1 \sim 0.1 \mathrm{~m} / \mathrm{s}$ appears. In the east slope of the south portion, there even exists a weak downflow, which is agreed with the uniform westerly wind during the daytime of 1 October shown in Figure 9c. After about 18:00 LST, the upflows in most areas of the mountain start changing to downflows, while the intensities of the downflows vary in the different portions of the mountain. This vertical motion inconformity further proves that the heterogeneity of the mountain terrain indeed causes the differences in mountain-valley breeze circulation. Corresponding with the nocturnal stronger divergence flow on the eastern slope in Figure $9 \mathrm{a}$, the stronger downflows show up on the eastern slope in the north portion of the mountain at 04:00 LST on 2 October.
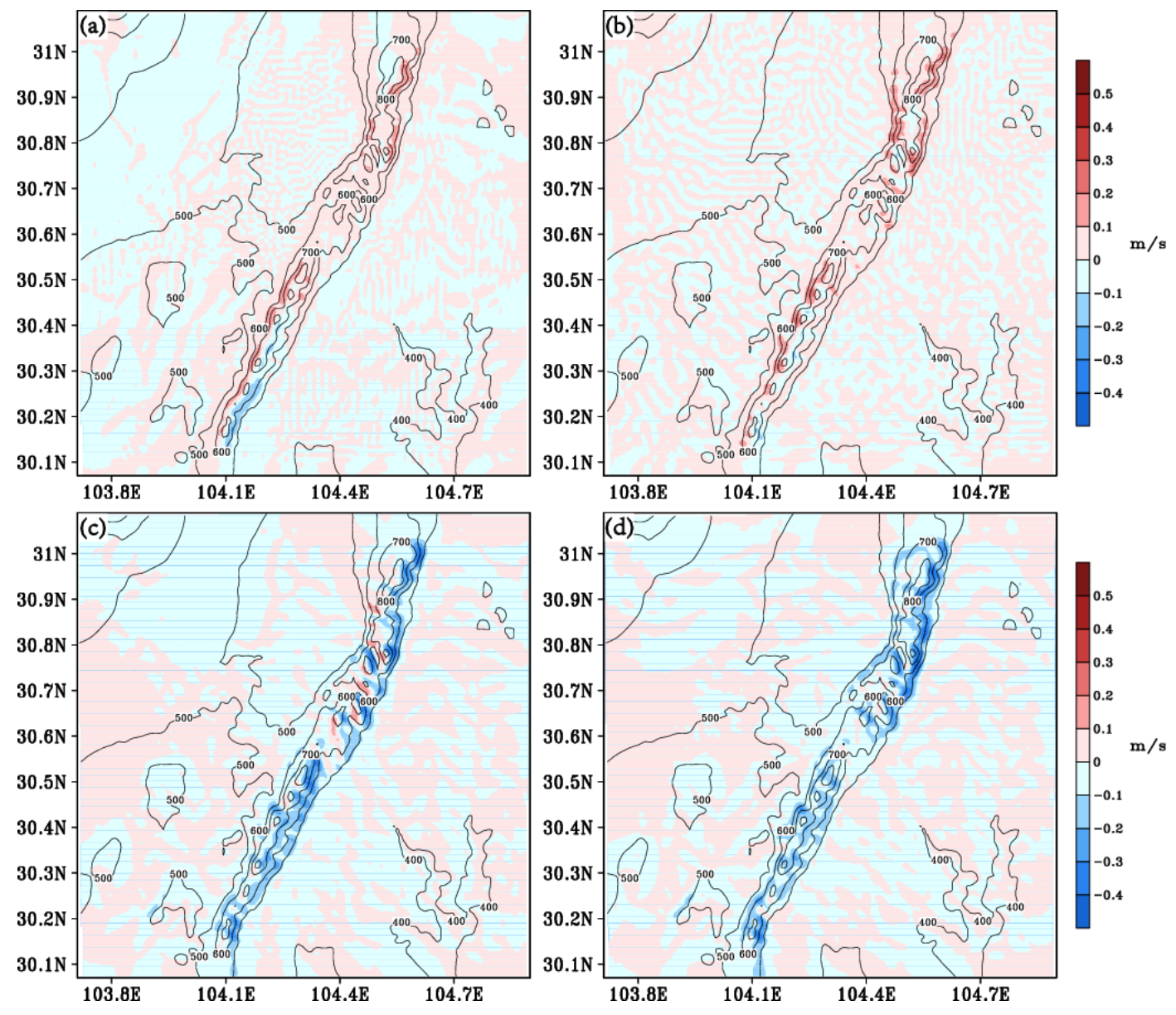

Figure 10. Vertical wind (shaded, units: m/s) on the first eta level at (a) 10:00 LST; (b) 16:00 LST; (c) 20:00 LST on 1 October, and (d) 04:00 LST on 2 October 2016; contour: terrain height (units: m).

Figure 11 shows the vertical cross section of the wind field (U- and W-components), potential temperature and water vapor mixing ratio along $30.9^{\circ} \mathrm{N}$. At 10:00 LST, the nocturnal stable boundary layer transforms into neutral or convective boundary layers and the atmospheric boundary layer rises up to a certain height. A horizontal thermal gradient between the mountain top and plain is established due to the difference in heating rate (Figure 11b). Prevailing easterly winds can be seen in the upper layer from the cross-section, overlies a shallower westerly flow on the western plain, which 
is gradually thickened in response to the turbulent movement induced by the heated ground surface. The flows on the western and eastern plains converge at the mountain top area. Coupling with the westerly flow, the plain breeze on the western plain leads to a stronger upflow compared to the eastern side, yet it is still not strong enough to arouse a well-defined plain breeze circulation at this moment (Figure 11a). As seen in Figure 11c, the maximum value of the water vapor mixing ratio occurs near the ground. The water vapor on the western slope is advected to a higher altitude by the stronger upflow compared to the eastern slope, causing a higher extent of the water vapor mixing ratio on the western slope.

At around 13:00 LST, the upflow of the plain breeze along $30.9^{\circ} \mathrm{N}$ grows stronger up to $1.8 \mathrm{~m} / \mathrm{s}$, while the plain breeze circulation at this moment is covered by the vigorous turbulent movement generated by the surface heating. At 16:00 LST (Figure 11d), compared to the morning period, the convergence flows appear more distinct and intense as well as the return flow according to the zero lines of U-component. At this moment, the updrafts can reach $1.2 \mathrm{~m} / \mathrm{s}$. Although the vertical turbulence reduces the tendency of the outer part of the plain breeze circulation, we can still discern the outer edge of the circulation by the zero lines of the U-component. The boundary layer elevates to a maximum height of $1516.4 \mathrm{~m}$ AGL (2008.4 m ASL) at this time, and the shallow westerly flow at 10:00 LST develops much thicker. Adler and Kalthoff [35] denote that the boundary layer over complex terrain is governed by multiple processes such as convection, thermally- and dynamically-driven flows, which are all responsible for the higher reaches of the boundary layer than the one over flat terrain. It is also well noted that, above the boundary layer (approximately from $2.1 \mathrm{~km}$ to $3 \mathrm{~km}$ AGL), a fluctuation forms downwind from the mountain top. This agrees with the findings of Conrick et al. [36] that the Kelvin-Helmholtz instability is likely to develop over complex terrain when there is a veering in wind direction. In Figure 11f, the water vapor mixing ratio distributes more evenly within the boundary layer, whereas the maximum value reduces compared to the morning time. The water vapor mixing ratio on the eastern slope is still distinctly less than that on the western slope.

After sunset, when solar radiation gradually weakens, the stable boundary layer establishes again from the bottom up, characterizing with the dense and horizontal isentropes (Figure 11h). The cold thermally-driven mountain breezes start blowing divergently from the mountain top to the plain on both sides at around 20:00 LST. An obvious anticlockwise flow circulation is induced in the eastern side of the mountain where the isentropes curve congruently as the lee side downflow (Figure 11g). At the same time, the mountain waves tend to develop vertically and tilt upwind with height. According to Jackson et al. and Adler and Kalthoff [37,38], the dynamically-driven downslope winds bring dryer and warmer air to the leeward slope due to the adiabatic motion and cause the concave portion of the isentropes. Since the synoptic background is moderately stable and no significant wind shear exists above the mountain top [37], vertically propagating mountain waves are formed on the leeward side of the mountain. To summarize, the anticlockwise circulation on the eastern flow is resulted from the coupling of mountain breezes and downslope winds. In terms of the water vapor mixing ratio, without the upflow in the daytime, the isolines of water vapor mixing ratio tend to be straight and flat (Figure 11i). The downslope wind on the leeward slope brings dryer air from the upper level to the lower level, leading to the concave shape on the eastern side of the mountain. The water vapor mixing ratio near the ground reaches its maximum before the sunrise. 

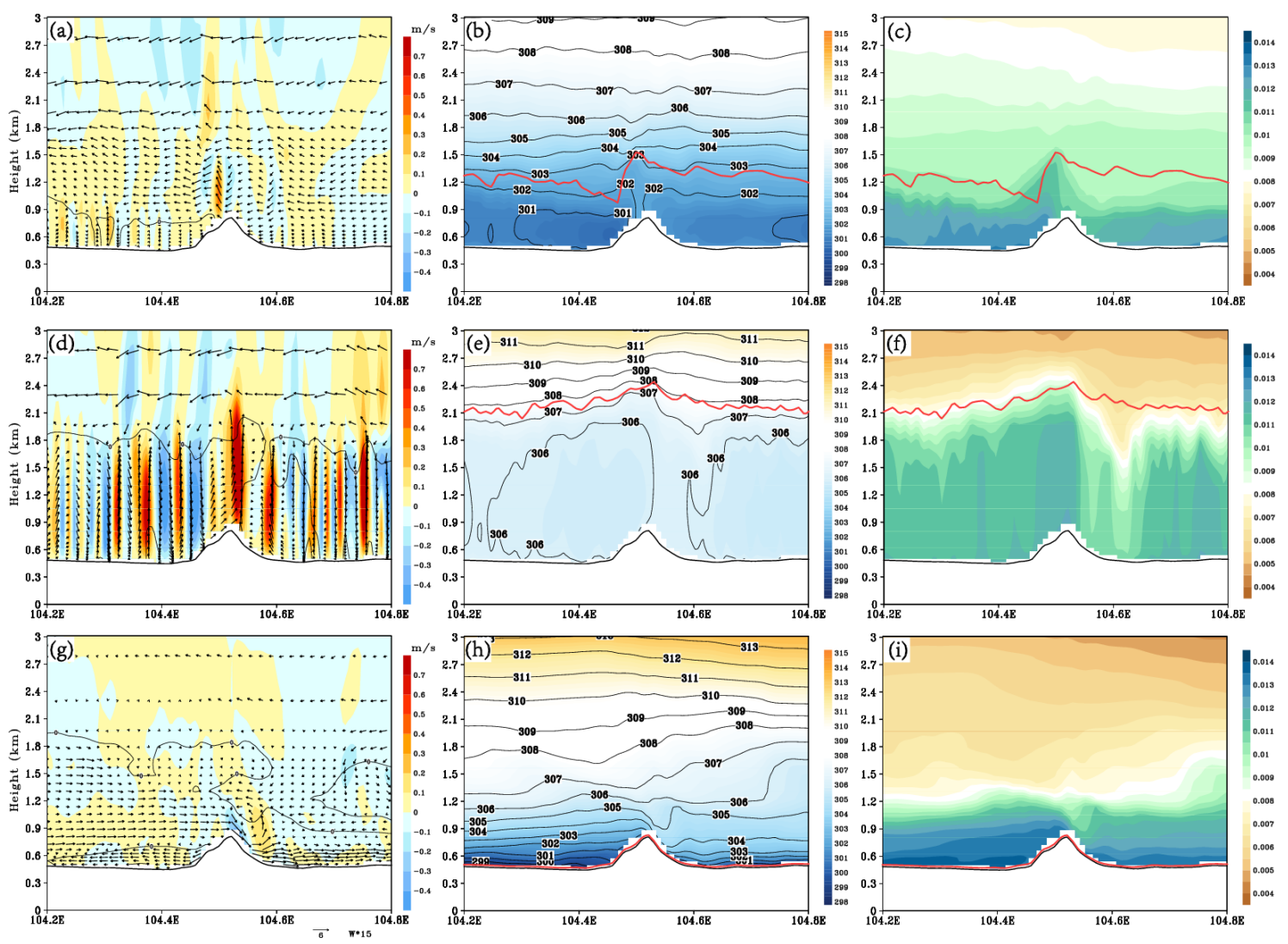

Figure 11. (a,d,g) Vertical cross sections of zonal wind speed (contour, units: $\mathrm{m} / \mathrm{s}$ ), vertical wind speed (shaded, units: m/s), wind field (vector, units: m/s, w times 15); (b,e,h) potential temperature (shaded, contour, units: $\mathrm{K})$; $(\mathbf{c}, \mathbf{f}, \mathbf{i})$ water vapor mixing ratio (shaded, units: $\mathrm{kg} / \mathrm{kg}$ ) and planetary boundary layer height (red solid line, units: $\mathrm{km})$ at $30.9^{\circ} \mathrm{N}$ at $(\mathbf{a}, \mathbf{b}, \mathbf{c})$ 10:00 LST; (d,e,f) 16:00 LST on 1 October, and $(\mathbf{g}, \mathbf{h}, \mathbf{i})$ 03:00 LST on 2 October 2016.

In general, the background wind forcing and the turbulent movement have a great influence on the behaviors of the mountain-plain breeze circulation, but are not sufficiently strong to prevent the formation and the emergence of it. Although the thermal circulation in the Longquan Mountain area is not as apparent as those in the large mountain chains due to the comparatively gentle terrain, the model is still able to capture the characteristics and the evolution of the local circulation. It is also worth reminding that the cross section discussed above only represents a fragment of the given latitude, the general behavior of the mountain-plain breeze circulation can be more clearly seen from Figures 7, 9 and 10.

\subsection{Turbulence Characteristics}

Turbulence can be generated thermally by buoyancy effects (thermally-driven mesoscale circulations during the daytime) and mechanically by shear (low-level jets during the nighttime and mountain waves) in mountainous regions $[19,39]$. At the same time, turbulence in the boundary layer plays an important role in the exchange of energy and pollutants. Therefore, the turbulence characteristic and the impact of turbulent fluxes on the mountain-plain breeze circulation in the study area are analyzed in this section.

In Figures 10 and 11, turbulences with the form of up-and-down, ruleless flows can be identified at both 10:00 and 16:00 LST. We first investigate TKE as a general measure of the turbulence intensity. In Figure 12a, the TKE is mainly distributed within the convective boundary layer during the daytime and is almost zero after sunset. At 14:00 LST on both of the days, the averaged TKE reaches the maximum value. 
Comparison of the averaged TKE profiles for mountain and plain regions at 14:00 LST is further performed, as shown in Figure 12b. In the range of tens of meters above the ground, the TKE increases with height since the dissipation rate in the TKE budget equation is largest near the surface during the daytime [40]. The height at which the maximum appears matches well with the conclusion in Figure 12a. For the mountain area, the value of the averaged TKE tends to be larger compared to the plain at two heights ranging approximately from the ground to $1200 \mathrm{~m}$ and from $1700 \mathrm{~m}$ to $2100 \mathrm{~m}$. In places with higher topographic height, air parcels within the boundary layer are more easily heated by the ground, resulting in a larger positive buoyancy term and a larger TKE value in the lower half of the boundary layer. As for the larger averaged TKE value of the mountain region in the upper boundary layer, it could be resulted from the effect of $\mathrm{KH}$ waves, after which can later degenerate into less organized turbulences [41].
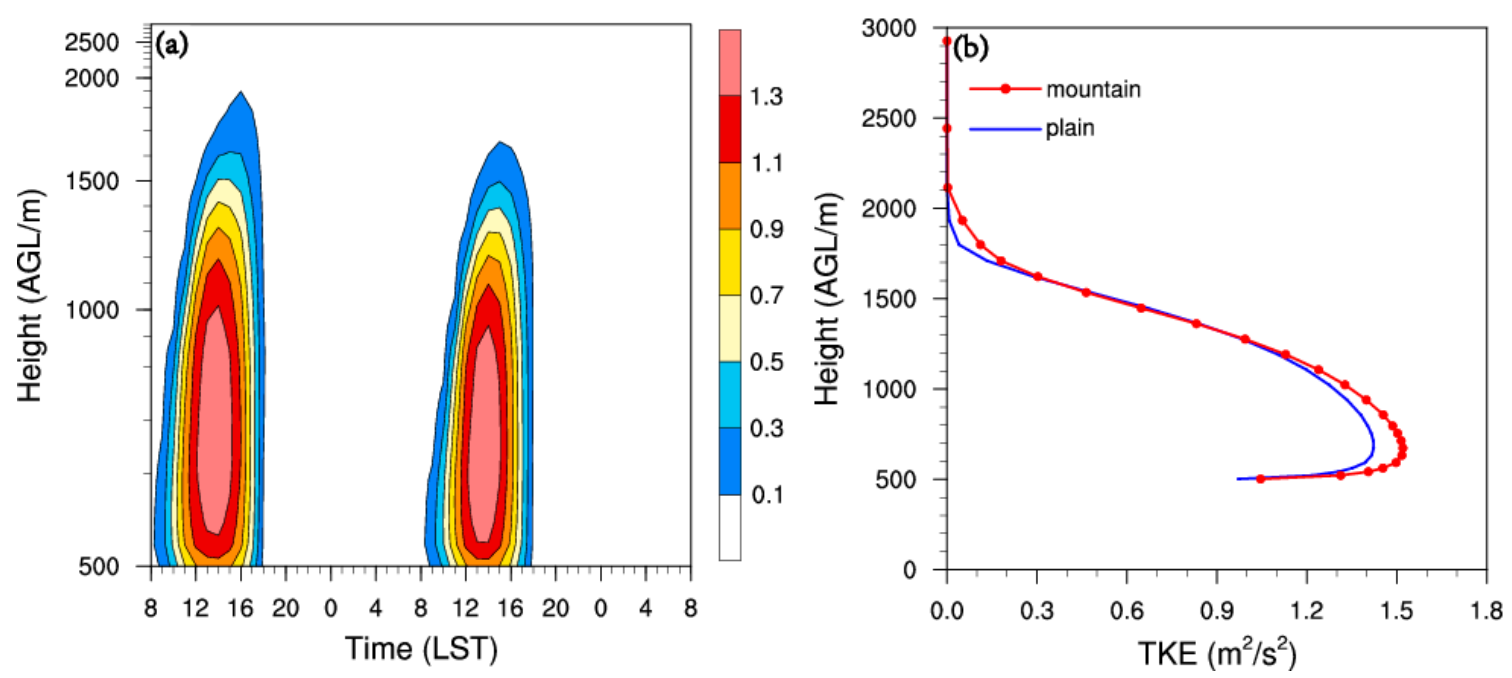

Figure 12. (a) Diurnal variation of the averaged TKE (shaded, units: $\mathrm{m}^{2} / \mathrm{s}^{2}$ ); (b) profile of area-averaged TKE (units: $\mathrm{m}^{2} / \mathrm{s}^{2}$ ) over the mountain and plain regions, respectively.

Since turbulence plays a crucial role in transferring the energy between the surface and the lower atmosphere, it modifies the distributions of these variables and the atmospheric stability. Therefore, we further examine the turbulent fluxes of heat, moisture, and momentum to elaborate on the formation and evolution of the local circulation.

In the parameterization of boundary layer turbulence, horizontal turbulent flux is often neglected compared to vertical turbulent flux since it is much less than the latter. The turbulence flux of any constituent $a$ can be represented as a covariance: $\overline{w^{\prime} a^{\prime}}$, an unresolved second-order moment in the movement equation representing the energy transport by turbulent eddies, where $w$ is the vertical velocity and the primes denote the fluctuation. For $\overline{w^{\prime} a^{\prime}}$ is negative, the constituent $a$ is transported downwards by the turbulence, and for $\overline{w^{\prime} a^{\prime}}$ is positive, it is transported upwards.

Figure 13 shows the cross-sections of the turbulent heat fluxes along $30.9^{\circ} \mathrm{N}$ and the diurnal cycle of the maximum turbulent heat flux and the height at which the maximum value appears. Potential temperature is used to measure the heat transport instead of virtual temperature since the latter includes the adiabatic variation. Usually, turbulent fluxes move quantities from higher to lower values. As the atmosphere above the convective boundary layer is stable, i.e., potential temperature increases with height, it is reasonable that the turbulent flux of potential temperature is negative throughout the lower atmosphere in the night or above the convective boundary layer in the daytime. 

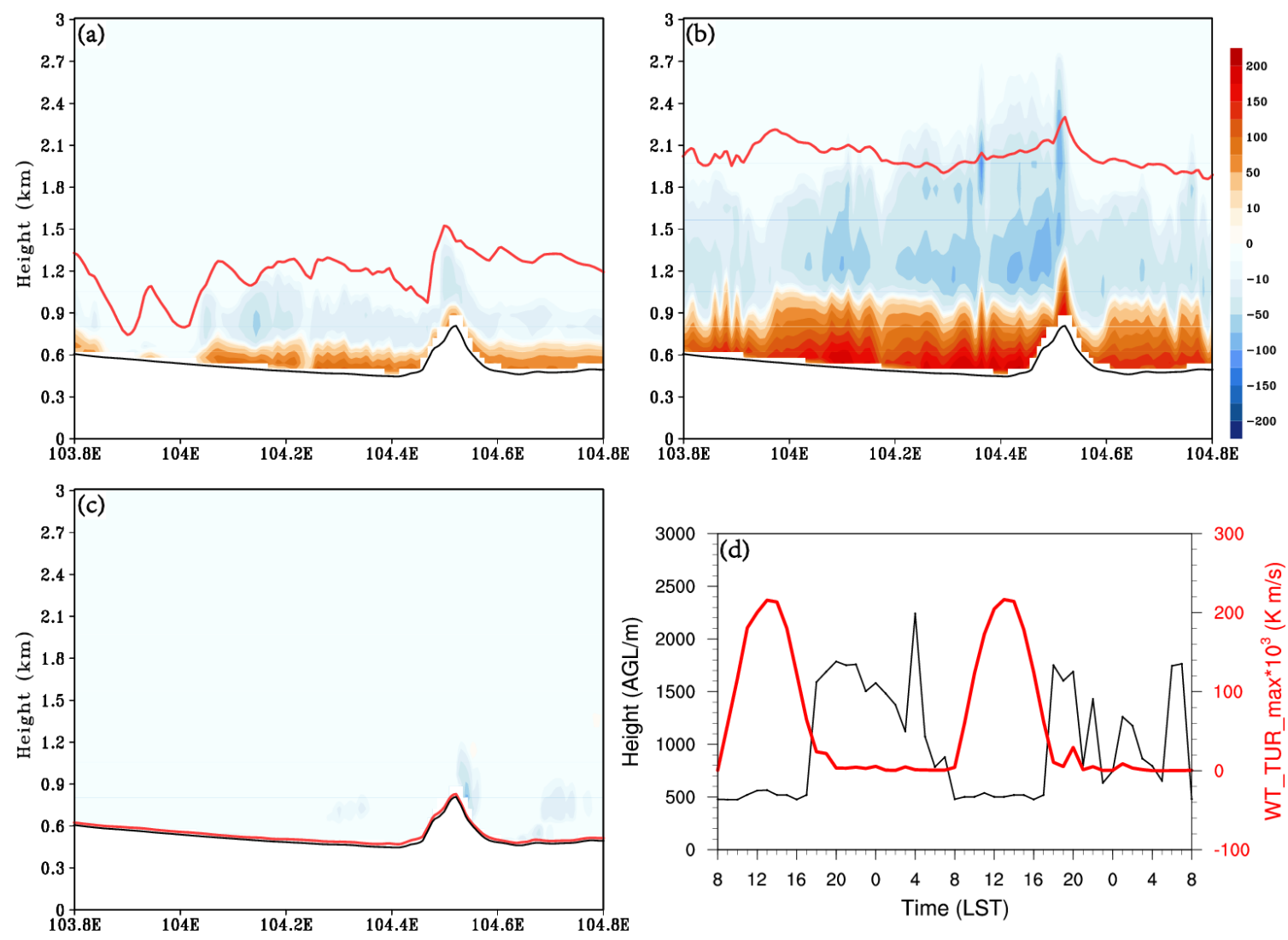

Figure 13. Vertical cross sections of turbulent heat flux (shaded, units: $10^{-3} \mathrm{~K} \cdot \mathrm{m} / \mathrm{s}$ ) and planetary boundary layer height (red solid line, units: $\mathrm{km}$ ) at $30.9^{\circ} \mathrm{N}$ at (a) 10:00 LST; (b) 14:00 LST on 1 October, and (c) 03:00 LST on 2 October 2016; (d) the height of the maximum turbulent heat flux (thin black line, units: $\mathrm{m}$ ) and the maximum value of the turbulent heat flux (thick red line, units: $10^{-3} \mathrm{~K} \cdot \mathrm{m} / \mathrm{s}$ ).

At 09:00 LST, positive turbulent fluxes of potential temperature start to establish near the surface and gradually develop upwards, since the ground surface acts as a heat source during the daytime. The air closest to the surface is heated first, then with the continuous heating, the heat energy accumulates and transfers to a higher level by turbulent eddies. Around this time, the turbulent heat fluxes in the upper half of the boundary layer appear to be negative, suggesting a substantial amount of air is entrained from the free atmosphere to the boundary layer [42]. The maximum of the turbulent fluxes of potential temperature locates near the surface, with the value of $0.2 \mathrm{~K} \mathrm{~m} / \mathrm{s}$ occurs at 13:00 LST. The conclusion can be further proved in Figure 13d. The maximum of turbulent heat flux shows a distinct diurnal cycle in these two days. The height of the maximum value does not change much during the day, and remains near the ground.

At around 18:00 LST, the positive values in the lower level of the boundary layer vanish. During the nighttime, the maximum value remains around zero, as seen in Figure 13d, while the height of the maximum value is large and irregular. In correspondence with the downslope flows in the nighttime, negative values of turbulent heat flux present on both sides of the mountain after 20:00 LST with larger absolute values on the eastern side, indicating weak eddies in nocturnal stable boundary layer moving warmer air downwards.

In general, the specific humidity is greatest near the surface and decreases with the height since the Earth's surface is also the moisture source. Hence, as shown in Figure 14, the turbulent moisture flux is positive in most situations. Similar to the turbulent heat flux, the biggish positive value of moisture flux near the ground appears at 09:00 LST and develops upward hereafter. At around 15:00 LST, the turbulent moisture flux reaches the maximum of $471.1 \times 10^{-6}-\mathrm{m} / \mathrm{s}$ and the height of the maximum value is $2221.4 \mathrm{~m}$. Unlike the vertical distribution of the water vapor mixing ratio, the position of 
maximum turbulent moisture flux is in the upper part of the boundary layer. Figure 14d generalizes this feature. As the maximum value of daytime turbulent moisture flux increases, the height at which the maximum value is located increases as well. Figure $14 \mathrm{~d}$ also shows that the position of maximum value keeps remaining at a certain height even if its value has already decreased at around 17:00-21:00 LST. The cause is that with the constant surface heating, a large amount of moisture is evaporated into the nearest air and result in a nearly saturated relative humidity, which in turn reduces the evaporation rate near the ground; the perturbed moisture that has been transferred to the midair remains at certain height while its value is decreasing. Therefore, we can see that over the mountain area and the downstream in a certain distance, the positive turbulent moisture flux can rises to a fairly high level and even penetrate into the free atmosphere in Figure 14b. This can be conducive to the reduction of local pollution condition.
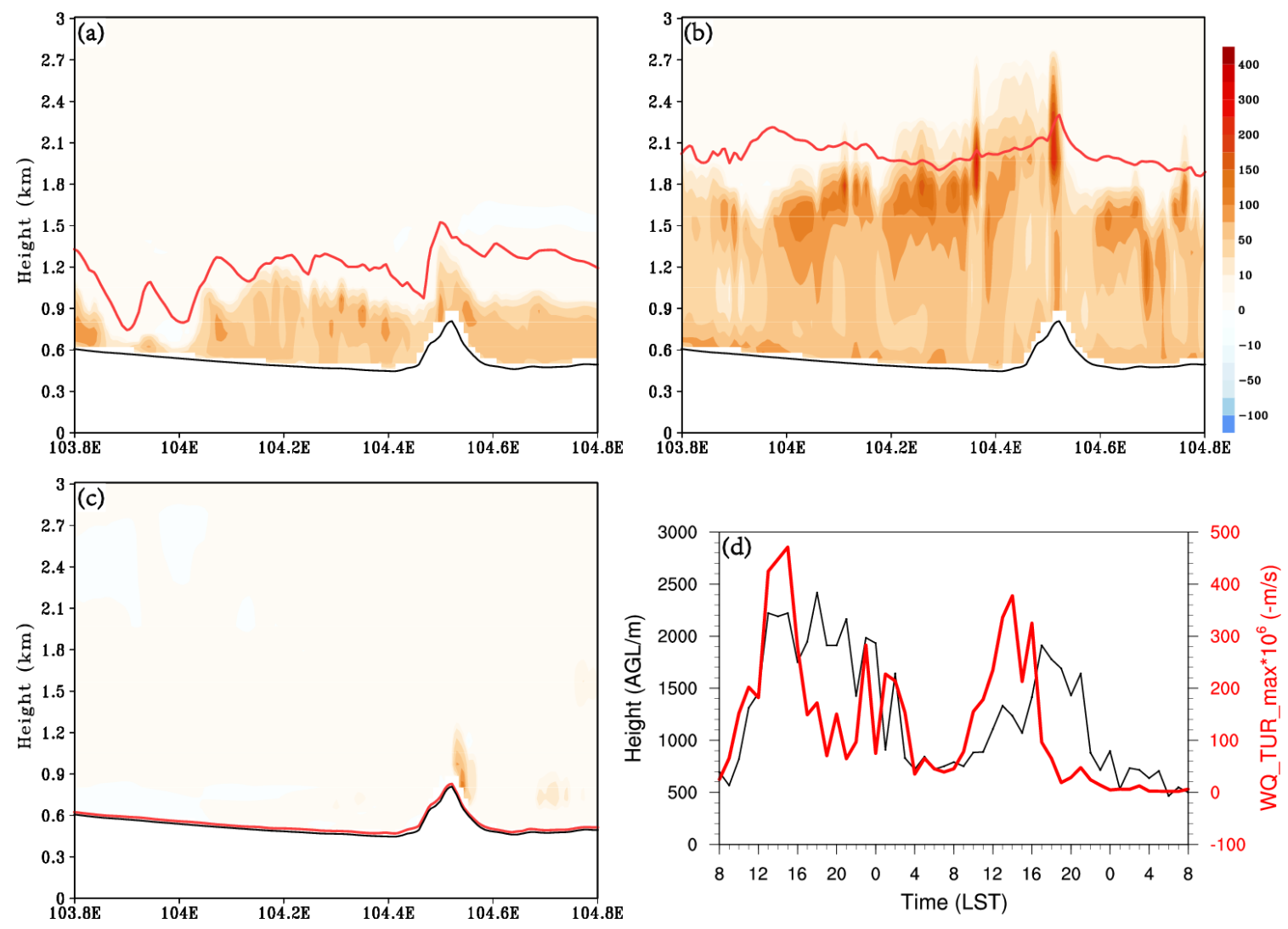

Figure 14. Same as Figure 13, but for turbulent moisture flux (units: $-10^{-6} \mathrm{~m} / \mathrm{s}$ ).

After 17:00 LST, the positive value begins to decrease significantly. A small range of positive turbulent moisture flux is predicted on the eastern side of the mountain from 03:00 to 06:00 LST on the next day since the leeward wind conveys the dry air from a higher altitude to the bottom of the mountain.

Figure 15 presents the turbulent momentum flux of U-component. Compared to the more uniformly distributed turbulent heat and moisture fluxes, the turbulent momentum flux shows more complexity around the mountain area. Doran et al. [15] considered that it is because turbulent momentum flux, which depends on both vertical and horizontal fluctuations, is more complicated than turbulent heat and moisture fluxes, which depend mainly on vertical fluctuations. 

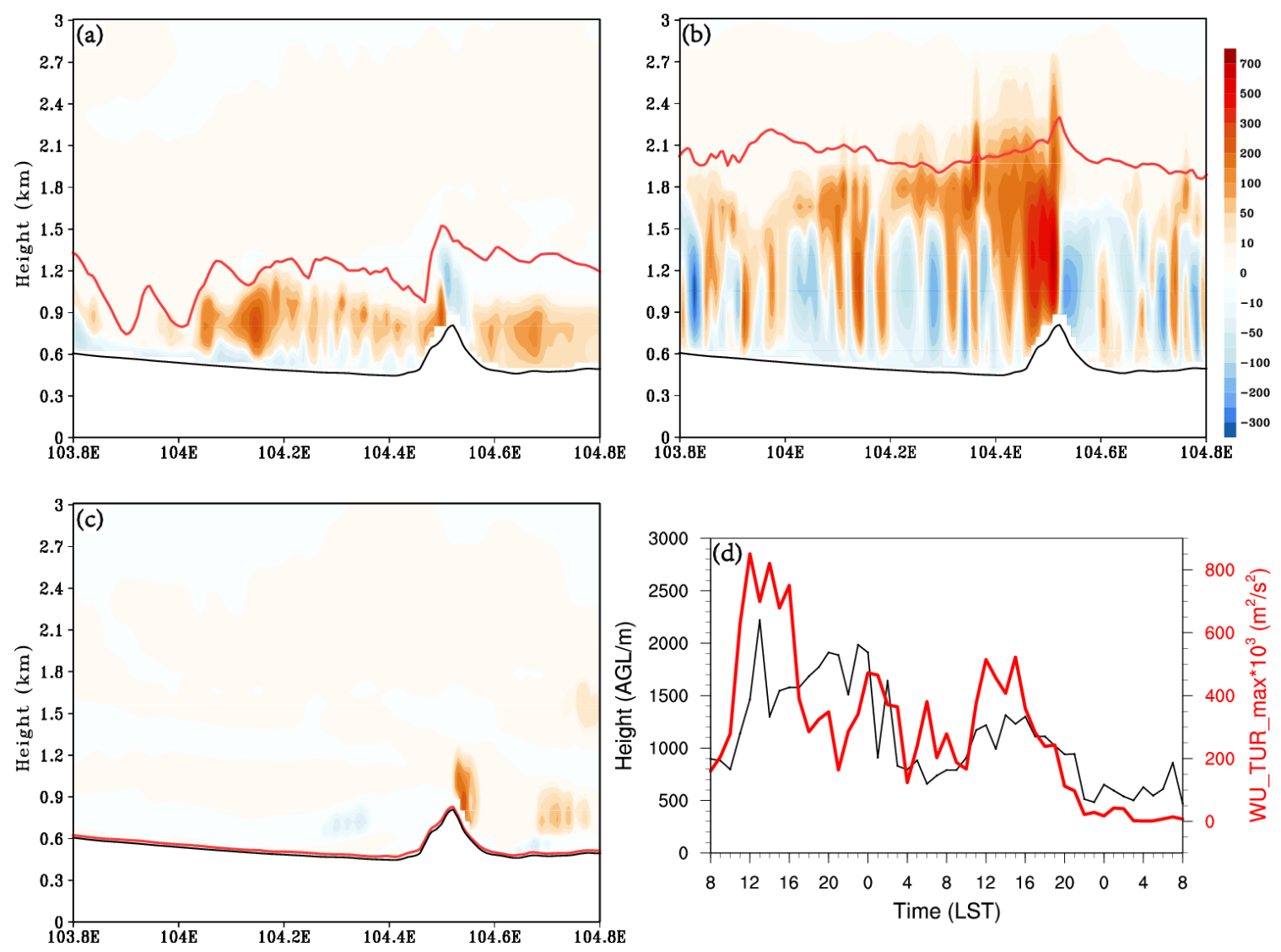

Figure 15. Same as Figure 13, but for turbulent momentum flux of U-component (units: $10^{-3} \mathrm{~m}^{2} / \mathrm{s}^{2}$ ).

A positive value within the convective boundary layer is predicted after 09:00 LST in the morning, indicating a momentum exchange between the boundary layer and the free atmosphere. In other words, perturbed westerly flows near the surface are propagated upwards, and the perturbed easterly flows in the free atmosphere are propagated downwards, under the impact of a turbulent motion. As shown in Figure 15b, the positive value is enhanced near the western slope, and a well-defined negative flux presents on the eastern slope. This flux pattern favors the maintenance of the plain breeze circulation, replenishing the momentum for the convergent upward flows. Later, when the surface heating weakens, this pattern subsequently collapses, causing the attenuation of the plain breeze circulation in the late afternoon. From 03:00 to 06:00 LST of the next day, a small range of positive turbulent momentum flux exists on the eastern slope in the nighttime, which means perturbed easterly flows are transported downwards and are accounted for the short duration and the weak strength of the nocturnal leeward breeze circulation.

The maximum turbulent momentum flux curve in Figure 15d presents larger values on the first day. This is partly due to the larger U-component in the free atmosphere, which results in stronger turbulent momentum exchange. Moreover, it is interesting that the maximum value increases again after 21:00 LST on the first day, with the higher height of the maximum value compared to the second day. This can be clearly seen in the turbulent heat and moisture curves. In the vertical cross-section of TKE (not shown), high TKE values can be found both above the mountain top and on the eastern slope at time corresponding with the strong vertically propagating mountain waves appears. Jackson et al. [37] reviewed past research regarding the dynamically-driven mountain waves, and showed that turbulences are easily generated in the breaking wave region and hydraulic jump region of the vertically propagating waves. This helps confirm and explain the existence of a large turbulent flux value and why it maintains at the upper level at night. It is worth mentioning that the turbulence above the mountain top, and on the downstream area might cause hazards when it 
reaches certain intensities. Also, downstream mountain wave rotors may kick up the dust on the surface, which could account for the poor air quality in Jianyang. Since this phenomenon does not show up on the second day, it is convinced that the vertically propagating mountain wave shows a strong dependence on synoptic conditions.

\section{Conclusions}

The characteristics and evolution of the mountain-plain breeze circulation in the Longquan Mountain, eastern Chengdu are studied by means of a three-dimensional high-resolution WRF (V3.9) numerical simulation under a clear-sky and weak-gradient condition. The presence of the strong ground inversion layer causes an unusual temperature distribution between the mountain and the plain area at night. Due to the terrain difference among different portions of the Longquan Mountain, the characteristics and evolution of the mountain-plain breeze circulations are different in various locations. The intensity of the mountain-plain breeze circulation in the Longquan Mountain is not as strong as those large mountain ranges, yet distinct upflows can be triggered at the mountain top in the afternoon. Strong downflows can form at night because of the coupling of thermally-driven mountain breezes and dynamically-driven downslope winds.

Significant temporal and spatial variability of TKE is revealed in this case and the attendant turbulent transport of momentum, heat, and moisture is studied. Averaged TKE value of the mountain region is larger than that of the plain region, indicating that stronger turbulences are formed over the mountain area. After sunrise, heat, and moisture are transported upwards by turbulent eddies, while their vertical distributions show obvious differences. The positive turbulent momentum flux on the western slope, and the negative turbulent momentum flux on the eastern slope together favor the development and maintenance of the plain breeze circulation during the daytime. In the late afternoon, as the turbulent momentum fluxes weaken, the plain breeze circulation gradually disappears.

Author Contributions: J.M. designed this study; Y.T. conducted numerical experiments, analyzed the data and drafted the manuscript under J.M.'s supervision and guidance; J.M. revised the manuscript.

Funding: This research was funded by National Key Research and Development Program of China, grant number 2016YFC0203304.

Acknowledgments: Sichuan Meteorological Bureau is thanked for providing the observational data, and three anonymous reviewers are greatly thanked for their valuable comments and suggestions to improve the manuscript.

Conflicts of Interest: The authors declare no conflict of interest.

\section{References}

1. Yang, Y.; Fan, J.W.; Leung, L.R.; Zhao, C.; Li, Z.Q.; Rosenfeld, D. Mechanisms contributing to suppressed precipitation in Mt. Hua of central China. Part I: Mountain valley circulation. J. Atmos. Sci. 2016, 73, 1351-1366. [CrossRef]

2. Jin, L.L.; Li, Z.J.; He, Q.; Miao, Q.L.; Zhang, H.Q.; Yang, X.H. Observation and simulation of near-surface wind and its variation with topography in Urumqi, West China. J. Meteorol. Res. 2016, 30, 961-982. [CrossRef]

3. Bei, N.F.; Zhao, L.N.; Wu, J.R.; Li, X.; Feng, T.; Li, G.H. Impacts of sea-land and mountain-valley circulations on the air pollution in Beijing-Tianjin-Hebei (BTH): A case study. Environ. Pollut. 2018, 234, 429-438. [CrossRef]

4. Xu, J.Z.; Assenova, A.; Erokhin, V. Renewable energy and sustainable development in a resource-abundant country: Challenges of wind power generation in Kazakhstan. Sustainability 2018, 10, 3315. [CrossRef]

5. Li, L.L.; Li, J.; Chen, H.M.; Yu, R.C. Diurnal variations of summer precipitation over the Qilian mountains in northwest China. J. Meteorol. Res. 2019, 33, 18-30. [CrossRef]

6. Vergeiner, I.; Dreiseitl, E. Valley winds and slope winds-Observations and elementary thoughts. Meteorol. Atmos. Phys. 1987, 36, 264-286. [CrossRef]

7. Zardi, D.; Whiteman, C.D. Diurnal mountain wind systems. In Mountain Weather Research and Forecasting; Chow, F.K., De Wekker, S.F., Snyder, B.J., Eds.; Springer Atmosphere Sciences; Springer: Dordrecht, The Netherlands, 2013; pp. 35-119. 
8. Tian, Y.; Miao, J.F. An overview of mountain-valley breeze studies in China. Meteorol. Sci. Technol. 2019, 47, 41-51.

9. Hernández-Ceballos, M.A.; Adame, J.A.; Bolívar, J.P.; De la Morena, B.A. A mesoscale simulation of coastal circulation in the Guadalquivir valley (southwestern Iberian Peninsula) using the WRF-ARW model. Atmos. Res. 2013, 124, 1-20. [CrossRef]

10. Isaksson, R. Numerical Simulation of Diurnal Planetary Boundary Layer Effects and Diurnal Mountain-Wind Effects. Ph.D. Thesis, Uppsala University, Uppsala, Sweden, 2016.

11. Whiteman, C.D.; Doran, J.C. The relationship between overlying synoptic-scale flows and winds within a valley. J. Appl. Meteorol. 1993, 32, 1669-1682. [CrossRef]

12. Liu, H.Z.; Liang, B.; Zhu, F.R.; Zhang, B.Y.; Sang, J.G. Water-tank experiment on the thermal circulation induced by the bottom heating in an asymmetric valley. Adv. Atmos. Sci. 2004, 21, 536-546. [CrossRef]

13. Wang, D.; Miao, J.F.; Zhang, D.L. Numerical simulations of local circulation and its response to land cover changes over the Yellow Mountains of China. J. Meteorol. Res. 2015, 29, 667-681. [CrossRef]

14. Sun, F.L.; Ma, Y.M.; Hu, Z.Y.; Li, M.S.; Tartari, G.; Salerno, F.; Gerken, T.; Bonasoni, P.; Cristofanelli, P.; Vuillermoz, E. Mechanism of daytime strong winds on the northern slopes of Himalayas, near Mount Everest: Observation and simulation. J. Appl. Meteorol. Climatol. 2018, 57, 255-272. [CrossRef]

15. Doran, J.C.; Wesely, M.L.; McMillen, R.T.; Neff, W.D. Measurements of turbulent heat and momentum fluxes in a mountain valley. J. Appl. Meteorol. 1989, 28, 438-444. [CrossRef]

16. Srivastava, M.K.; Sarthi, P.P. Turbulent kinetic energy in the atmospheric surface layer during the summer monsoon. Meteorol. Appl. 2002, 9, 239-246. [CrossRef]

17. Večenaj, Ž.; De Wekker, S.F.J.; Grubišić, V. Near-surface characteristics of the turbulence structure during a mountain-wave event. J. Appl. Meteorol. Climatol. 2011, 50, 1088-1106. [CrossRef]

18. Lehner, M.; Rotach, M.W. Current challenges in understanding and predicting transport and exchange in the atmosphere over mountainous terrain. Atmosphere 2018, 9, 276. [CrossRef]

19. Serafin, S.; Adler, B.; Cuxart, J.; De Wekker, S.F.J.; Gohm, A.; Grisogono, B.; Kalthoff, N.; Kirshbaum, D.J.; Rotach, M.W.; Schmidli, J.; et al. Exchange processes in the atmospheric boundary layer over mountainous terrain. Atmosphere 2018, 9, 102. [CrossRef]

20. Dörnbrack, A. Turbulent mixing by breaking gravity waves. J. Fluid Mech. 1998, 375, 113-141. [CrossRef]

21. Kirkwood, S.; Mihalikova, M.; Rao, T.N.; Satheesan, K. Turbulence associated with mountain waves over Northern Scandinavia-A case study using the ESRAD VHF radar and the WRF mesoscale model. Atmos. Chem. Phys. 2010, 10, 3583-3599. [CrossRef]

22. Zeng, S.L. Characteristics of urban heat island effect in Chengdu. J. Chengdu Univ. Inf. Technol. 2015, 30, 96-101.

23. Balanzino, A.; Castelli, S.T. Numerical experiments with RAMS model in highly complex terrain. Environ. Fluid Mech. 2018, 18, 357-381. [CrossRef]

24. Schmidli, J.; Böing, S.; Fuhrer, O. Accuracy of simulated diurnal valley winds in the Swiss Alps: Influence of grid resolution, topography filtering, and land surface datasets. Atmosphere 2018, 9, 196. [CrossRef]

25. Lee, S.-J.; Berbery, E.H. Land cover change effects on the climate of the La Plata Basin. J. Hydrometeorol. 2012, 13, 84-102. [CrossRef]

26. Su, T.; Miao, J.F.; Wang, Y.H. Impact of radiative transfer parameterizations on simulated sea breeze thunderstorm over the Hainan island. Chin. J. Geophys. 2017, 60, 3023-3040.

27. Bougeault, P.; Lacarrère, P. Parameterization of orography-induced turbulence in a mesobeta-scale model. Mon. Weather Rev. 1989, 117, 1872-1890. [CrossRef]

28. Shin, H.H.; Hong, S.Y. Intercomparison of planetary boundary-layer parametrizations in the WRF model for a single day from CASES-99. Bound. -Layer Meteorol. 2011, 139, 261-281. [CrossRef]

29. Večenaj, Ž.; Belušić, D.; Grubišić, V.; Grisogono, B. Along-coast features of bora-related turbulence. Bound. -Layer Meteorol. 2012, 143, 527-545.

30. Yang, Q.Y.; Miao, J.F.; Wang, Y.H. Impact of planetary boundary layer parameterizations on simulated sea breeze circulation over the Hainan Island. J. Trop. Meteorol. 2019, 35, $234-252$.

31. Prasad, K.B.R.R.H.; Srinivas, C.V.; Naidu, C.V.; Baskaran, R.; Venkatraman, B. Assessment of surface layer parameterizations in ARW using micro-meteorological observations from a tropical station. Meteorol. Appl. 2016, 23, 191-208. [CrossRef] 
32. Wang, Y.; Miao, J.F. Impact of surface layer parameterizations on simulated sea breeze precipitation over the Hainan island. Chin. J. Geophys. 2019, 62, 32-48.

33. Jeong, J.; Lee, S.-J. A statistical parameter correction technique for WRF medium-range prediction of near-surface temperature and wind speed using generalized linear model. Atmosphere 2018, 9, 291. [CrossRef]

34. Liu, X.J.; Tian, G.J.; Feng, J.M.; Wang, J.; Kong, L.Q. Assessing summertime urban warming and the cooling efficacy of adaptation strategy in the Chengdu-Chongqing metropolitan region of China. Sci. Total Environ. 2018, 610-611, 1092-1102. [CrossRef] [PubMed]

35. Adler, B.; Kalthoff, N. Multi-scale transport processes observed in the boundary layer over a mountainous island. Bound. Layer Meteorol. 2014, 153, 515-537. [CrossRef]

36. Conrick, R.; Mass, C.F.; Zhong, Q. Simulated Kelvin-Helmholtz waves over terrain and their microphysical implications. J. Atmos. Sci. 2018, 75, 2787-2800. [CrossRef]

37. Jackson, R.L.; Mayr, G.; Vosper, S. Dynamically-Driven Winds. In Mountain Weather Research and Forecasting; Chow, F.K., De Wekker, S.F., Snyder, B.J., Eds.; Springer Atmosphere Sciences; Springer: Dordrecht, The Netherlands, 2013; pp. 121-218.

38. Adler, B.; Kalthoff, N. The impact of upstream flow on the atmospheric boundary layer in a valley on a mountainous island. Bound. Layer Meteorol. 2016, 158, 429-452. [CrossRef]

39. Lampert, A.; Pätzold, F.; Jiménez, M.A.; Lobitz, L.; Martin, S.; Lohmann, G.; Canut, G.; Legain, D.; Bange, J.; Martínez-Villagrasa, D.; et al. A study of local turbulence and anisotropy during the afternoon and evening transition with an unmanned aerial system and mesoscale simulation. Atmos. Chem. Phys. 2016, 16, 8009-8021. [CrossRef]

40. Rai, R.K.; Berg, L.K.; Pekour, M.; Shaw, W.J.; Kosovic, B.; Mirocha, J.D.; Ennis, B.L. Spatiotemporal variability of turbulence kinetic energy budgets in the convective boundary layer over both simple and complex terrain. J. Appl. Meteorol. Climatol. 2017, 56, 3285-3302. [CrossRef]

41. Douglas, K.L. Instabilities. In Mesoscale Meteorology and Forecasting; Ray, P.S., Ed.; American Meteorological Society: Boston, MA, USA, 1986; pp. 259-271.

42. Kaimal, J.C.; Wyngaard, J.C.; Haugen, D.A.; Coté, O.R.; Izumi, Y. Turbulence structure in the convective boundary layer. J. Atmos. Sci. 1976, 33, 2152-2169. [CrossRef]

(C) 2019 by the authors. Licensee MDPI, Basel, Switzerland. This article is an open access article distributed under the terms and conditions of the Creative Commons Attribution (CC BY) license (http://creativecommons.org/licenses/by/4.0/). 